\title{
Memory deficits following diazepam administration in mice: Evidence for a time-dependent retrieval impairment
}

\author{
N. BORDE \\ Université de Bordeaux I, Talence, France \\ A. KRAZEM \\ Université de Tizi-Ouzou, Tizi-Ouzou, Algeria \\ and \\ A. JAFFARD and D. J. BÉRACOCHÉA \\ Université de Bordeaux I, Talence, France
}

\begin{abstract}
The aims of this study were to examine the effects of systemic injection of diazepam on memory as measured by the intrasession evolution of alternation response rates in both sequential and delayed procedures. We showed that diazepam injection produced delay-dependent impairments in both sequential and delayed alternation protocols. However, the delayed alternation deficit produced by diazepam was totally alleviated by an intramaze context change occurring only before the retention trial. The memory-enhancing effect of the intramaze context change in experimental mice demonstrated that diazepam injection induced, during the usual testing (no-context change) conditions, a time-dependent retrieval memory deficit.
\end{abstract}

Several studies have been carried out to determine the effects of administering benzodiazepines (BDZ) agonists and antagonists on memory in humans. Specifically, these studies aimed at comparing the types of memory impairment induced by BDZ compounds with the forms of memory dysfunctions observed in organic amnesia. It has been shown that the administration of $\mathrm{BDZ}$ compounds in humans produces deficits in episodic memory, but not in semantic or procedural memory (Danion et al., 1993; Lister, 1985; Polster, McCarthy, O'Sullivan, Gray, \& Park, 1993). Other studies have shown that BDZ administration produced deficits in explicit memory tasks but not in implicit memory (Danion, Zimmermann, WillardSchroeder, Grangé, \& Singer, 1989; Fang, Hinrichs, \& Gonheim, 1987; Polster et al., 1993; but see M. W. Brown, J. Brown, \& Bowes, 1989; Gonheim, Block, Sum Ping, El-Zahaby, \& Hinrichs, 1993). Taken together, these findings are congruent with the patterns of memory dysfunctions observed in organic amnesia (Schacter, 1987).

Most of these studies have suggested that BDZinduced memory impairment is predominantly due to deficits occurring at the encoding phase of memory pro-

This research was supported by the CNRS, URA 339. Correspondence should be addressed to D. J. Béracochéa, Laboratoire de Neurosciences Comportementales et Cognitives, URA CNRS 339, Université de Bordeaux I, UFR de Biologie Animale, Avenue des Facultés, 33405 Talence, France.

-Accepted by previous editor. Paul E. Gold cesses rather than during retrieval processes. This agreement was based on observations that $\mathrm{BDZ}$ diminishes anterograde recall and recognition without affecting retrograde memory - that is, memory of events occurring before the drug administration (Twersky, Hartung, Berger, McClain, \& Beaton, 1993; see also Gonheim \& Mewaldt, 1975; Gonheim, Hinrichs, \& Mewaldt, 1984). Animal studies have supported this view, reporting that memory impairment was observed when BDZ agents were delivered prior to the acquisition session but not prior to the test session (Belzung, Misslin, Vogel, Dodd, \& Chapouthier, 1987; Chapouthier \& Martin, 1992; Chapouthier, Raffalli-Sebille, Venault, Simiand, \& Dodd, 1991; Thiebot, 1985; Venault et al., 1986). However, in spite of these data, there still exist conflicting findings about the real effect of $\mathrm{BDZ}$ on retrograde and anterograde memories. Indeed, on one hand, some studies have mentioned retrograde impairments whereas other studies have not reported anterograde amnesia following BDZ administration; on the other hand, some studies have demonstrated retrievalrelated memory impairments in BDZ-administered human subjects (File, Skelly, \& Girdler, 1992), whereas studies demonstrating anterograde amnesia in animals have not determined the phase of memory processes (encoding, storage, retrieval) impaired by the drug. Moreover, some studies have even shown that memory performance in BDZ-administered animals was not sensitive to the length of the retention interval (Dudchenko \& Sarter, 1992; Herremans, Hijzen, Olivier, \& Slangen, 1995).

The failure to find retrograde amnesia following BDZ administration in animals may be due to the nature of the 
task used. Indeed, most of the experiments carried out on animals have mainly used single-trial learning tasks involving strong negative reinforcement or operant conditioning based on extensive prior training. These tasks involve several methodological problems that render data interpretation difficult. First, it is very difficult, in singletrial paradigms such as passive avoidance, to dissociate the memory component of the task (avoidance of the dark compartment) from the nonspecific emotionally conditioned response resulting from the electric shock (Jaffard \& Cardo, 1976), and more particularly following the administration of compounds modulating anxiety. Second, it is known that, once acquired and consolidated, memory in behavioral paradigms involving intensive training and/or procedural memory is quite resistant to amnestic treatments. Indeed, in these tasks, the to-beremembered information is no longer episodic in nature and/or is sustained purely by procedural knowledge at the time of retrieval. As mentioned by some authors (Kesner, 1986; Morris, 1983), for the majority of the tasks that are routinely used in studies of memory and learning in animals, the two distinct forms of memory, reference (semantic) versus working (episodic) memory, will constantly interact with each other throughout the learning of a given task. The proportional contribution of one type of memory relative to the other will undoubtedly vary as a function of the stage of task acquisition. In other words, the state of the animal in terms of the amount of prior training received is of great importance, since a given pharmacological treatment may have a detrimental effect at one stage of memory processing (the acquisition step) but not at another stage (retrieval step), depending on the relative importance of the episodic versus procedural memory component at the time the treatment is delivered. According to Sarter (1990), retrieval of welllearned propositional rules is comparable to the automatic and implicit reactivation of nondeclarative information in humans; this process depends on multiple internal representations and therefore remains relatively insensitive to manipulations of individual neurotransmitter systems.

In line with this idea, several studies using tasks involving spatial working memory processes have reported retrograde amnesia following the administration of drugs acting on the GABA/benzodiazepine receptors, using protocols that clearly obviate any possibility of acquisition impairments. Stackman and Walsh (1992) reported retention deficits following postacquisition chlordiazepoxide administration. In their behavioral procedure, rats were allowed to visit four arms of an 8-arm radial maze; after a $1-h$ delay, rats were allowed to complete the visit of the maze - to enter the remaining nonvisited four arms. Results indicated that an i.p. administration of chlordiazepoxide at doses of $2.5 \mathrm{or} 5.0 \mathrm{mg} / \mathrm{kg}$ following the presentation phase produced deficits in choice accuracy. In a similar memory task, Chrobak and Napier (1992) reported amnesia following postacquisition administration of $3.0-$ and $5.0-\mathrm{mg} / \mathrm{kg}$ chlordiazepoxide i.p. in the same working memory task. According to these authors, the administration of agents acting on GABA/benzodiazepine receptors disrupts the neuronal mechanisms involved in working/episodic memory processes, which normally sustain accurate performance in this task. Thus, the retrograde deficit was observed in these experiments because the information to be remembered was not fully consolidated, and it reflected in fact the development of an anterograde amnesia.

Thus, given the lack of convergent findings on the mechanism of the disruptive effects of $\mathrm{BDZ}$ injection on anterograde memory, both on the rate of forgetting and on the phase of memory processes impaired by the drug, the specific aims of the present study were to determine whether diazepam administration could produce delaydependent memory impairments in mice and to determine whether these eventual deficits might be related to an impairment of the retrieval phase of memory processes.

The tasks used to evaluate memory are based on spontaneous alternation behavior. Spontaneous alternation is the innate tendency of rodents to alternate on each trial, over a series of successive runs in a T-maze, the choice of the visited goal arm. This behavior has been widely studied to estimate rates of forgetting and/or sensitivity to proactive interference (Béracochéa \& Jaffard, 1987; Divac, Witmark, \& Gade, 1975; Thomas, 1984). In the present study, mice were submitted to both sequential and delayed alternation procedures, which in the past have allowed us to demonstrate delay-dependent memory deficits as well as retrieval impairments in alcohol-treated or diencephalic-lesioned mice (Béracochéa \& Jaffard, 1985; Béracochéa, Krazem, \& Jaffard, 1995; Béracochéa, Lescaudron, Tako, Verna, \& Jaffard, 1987; Béracochéa, Tako, \& Jaffard, 1989; Tako, Béracochéa, \& Jaffard, $1988)$. The sequential and delayed alternation procedures both involve a "working/episodic" memory component since in order to alternate, animals are required to remember specific information that varies from trial to trial (sequential procedure) or from session to session (delayed alternation procedure; O'Keefe, 1979; Thomas 1984). In addition, mice were also subjected, in parallel to memory testing, to behavioral tasks allowing us to measure emotional reactivity. Indeed, spontaneous alternation is based on innate exploration tendencies, and it has been shown that exploratory behavior is modulated by drugs having anxiolytic or anxiogenic effects (Gray, 1982). Thus, in order to determine whether eventual amnesic effects of diazepam administration in the spontaneous alternation tasks are related to the emotional effects of the drug, it is necessary to assess whether the doses of diazepam used in the present study have anxiolytic effects.

\section{EXPERIMENT 1 \\ Effects of Diazepam Injection on Emotional Reactivity and Sequential Alternation}

\section{Method}

\section{Subjects}

This study was conducted using male mice of the BALB/c strain received at 6 weeks of age from Iffa-Credo (Lyon, France). On ar- 
rival, mice were housed collectively in colony cages $(40 \mathrm{~cm}$ long, $25 \mathrm{~cm}$ high, and $20 \mathrm{~cm}$ wide), matched for weight, and placed in an animal room (ambient temperature, $22^{\circ} \mathrm{C}$; automatic light cycle, 12:12-h light:dark cycle) with free access to food and water. At least 2 weeks before behavioral testing began, mice were housed in individual cages, with free access to food and water.

\section{Emotional Reactivity}

Elevated plus-maze. The plus-maze, which was constructed of gray Plexiglas, consisted of four arms arranged in the shape of a plus sign. Each arm was $30 \mathrm{~cm}$ long, $7 \mathrm{~cm}$ wide, and elevated $40 \mathrm{~cm}$ above the ground. The four arms were joined at the center by a 7 -cm-square platform. Two opposite arms of the plus-maze were "closed" by sidewalls $17 \mathrm{~cm}$ high, but open on the top, and the remaining arms did not have sidewalls. These walls did not extend the center of the maze. At the beginning of each test, mice were placed in the center of the maze in a cylinder $(8 \mathrm{~cm}$ in diameter, $17 \mathrm{~cm}$ high) for $30 \mathrm{sec}$. Then, the cylinder was removed and mice were allowed to freely cxplore all arms of the maze for $10 \mathrm{~min}$. Activity and latencies were measured by the experimenters using semiautomatic counters and timers. An entry was counted only when a mouse entered an arm with all four feet. Two measures of "anxiety" were taken. The first was the ratio of the time spent in the open arms divided by the total time spent in all arms of the maze (time ratio). The second was the ratio of entries into the open arms divided by the total number of entries into all arms (ratio entries). Thus, the smaller these ratios, the more "anxious" the mouse (Pellow, Chopin, File, \& Briley, 1985).

Open-field. The open-field chamber was constructed of wood in the shape of a square measuring $120 \mathrm{~cm}$ per side. The floor was painted white and divided into 64 squares by black lines drawn on the floor. Illumination was provided by two lamps positioned $2 \mathrm{~m}$ above the apparatus and providing a 600 lux illumination equally distributed over the whole surface of the apparatus. At the start of each trial, animals were placed in the center of the apparatus in a small cylinder. Following a 30-sec delay, the cylinder was removed and the subjects were allowed to freely explore the apparatus for $10 \mathrm{~min}$. Two measures were taken. First, the total number of squares crossed by the subjects was counted as an index of activity. Second, the number of fecal boli recovered after the 10-min period was used as an index of emotionality (Dennenberg, 1969).

\section{Memory}

Sequential alternation. The sequential alternation procedure makes it possible to distinguish between the ability to alternate per se (second trials of a series) from the progressive inability to do so as the number of trials increases. In the latter case, repetitive testing (i.e., sequences of more than two trials) constitutes a potent source of proactive interference since the response on trial $n$ (which depends on information received on trial $n-1$ ) may be influenced by all previous information received from trial 1 to $n-2$. This procedure is analogous to classic behavioral paradigms used to study interference effects on memory in rats (Grant, 1981; Roberts \& Dale, 1981).

The task was performed in a T-maze constructed of gray Plexiglas ( $30 \mathrm{~cm}$ long, $10 \mathrm{~cm}$ wide, and $25 \mathrm{~cm}$ high). In the first procedure, all subjects were submitted to daily sessions of nine successive trials (sequential procedure) separated either by a $30-\mathrm{sec}$ intertrial interval (ITI; six first trials) or by a 5-sec ITI (three last trials of the series). A reverse condition was also tested (second procedure), in which the six first trials were separated by a 5 -sec ITI and the three remaining trials (7-9) were separated by a $30-$ sec ITI. These two procedures made it possible to determine the importance of the delay interval on performance as a function of the place of the trials in the series.

To begin a trial, the subjects were placed in the start box $(10 \times$ $12 \mathrm{~cm}$ ) for a $30-\mathrm{sec}$ or $5-\mathrm{sec}$ ITI as a function of the procedure used. Once this time had elapsed, the door to the stem was opened.
When the mouse entered one of the arms, the door to that arm was closed. Mice remained in the goal arm for $30 \mathrm{sec}$. Once this time had elapsed, the mouse was removed and placed in the start box for a new trial. An alternation response was quantified each time the subject entered the arm opposite to the one visited at the trial just visited. Individual alternation scores were averaged to determine the mean percent sequential alternation rate corresponding to a given group. The study was performed using independent groups of mice.

\section{Experimental Design}

Each subject of Experiment 1 was first submitted to the openfield task and then to the elevated plus-maze task followed by the sequential alternation task. The three tasks were run within a single period of $40 \mathrm{~min}$. The open-field, elevated plus-maze, and sequential alternation tasks were each run in different rooms. Each mouse was tested only once in each task. Animals were not food deprived during the experiments. Two days before being submitted to behavioral testing and drug administration procedures, as described above, animals were given two free exploration sessions of the T-maze (one daily session) of $10 \mathrm{~min}$ each in order to familiarize them with the apparatus. The task sequence was determined on the basis of a preliminary study using undrugged subjects. This study showed that performance in the open-field and elevated plusmaze tasks was not sensitive to the position of the task in the series, whereas sequential alternation rates were higher when sequential alternation was placed last as compared with the first or second positions.

\section{Drugs}

Diazepam (ROCHE) was dissolved in $0.9 \% \mathrm{NaCl}$ and diluted to the final concentration immediately before use. The saline group received only $\mathrm{NaCl}$ administration. Each mouse was treated only once. Drug and saline were injected i.p. in a volume of $0.05 \mathrm{ml} / 10 \mathrm{~g}$, $30 \mathrm{~min}$ before behavioral testing.

\section{Statistical Analysis}

Results were analyzed on transformed data (arcsin) of the percent sequential alternation scores followed by analysis of variance (ANOVA). Comparisons between individual groups were made with the Fisher PLSD test after factorial or repeated ANOVA.

\section{Emotional Reactivity \\ Results \\ Open-field. Results from the open-field task are sum-} marized in Table 1. Diazepam administration resulted in a highly significant reduction in the number of fecal boli [three groups treated with diazepam + saline groups; $F(3,81)=43.5, p<.001]$, together with an increase in activity $[F(3,81)=7.5, p<.001]$.

Elevated plus-maze. Results for the elevated plusmaze task are summarized in Table 1. Administration of diazepam increased both the activity ratio [groups; $F(3,81)$ $=12.1, p<.001]$ and time ratio $[F(3,81)=37.1, p<.001]$. Total activity was not significantly different among the groups $[F(3,81)=1.9, p=.13]$. Taken together, the results from the open-field and the elevated plus-maze tasks showed that the doses of diazepam used in our study had anxiolytic effects in both tasks.

\section{Memory: Sequential T-Maze Alternation}

In the first procedure, the six first trials were separated by a $30-\mathrm{sec}$ ITI, whereas the last three trials were separated by a 5 -sec ITI. 
Table 1

Means and SEMs for the Open-Field and Elevated Plus-Maze Tasks

\begin{tabular}{|c|c|c|c|c|c|c|c|c|c|c|c|}
\hline \multirow[b]{3}{*}{ Group } & \multirow[b]{3}{*}{$n$} & \multicolumn{4}{|c|}{ Open-Field Task } & \multicolumn{6}{|c|}{ Elevated Plus-Maze Task } \\
\hline & & \multicolumn{2}{|c|}{ Activity } & \multicolumn{2}{|c|}{ Fecal Boli } & \multicolumn{2}{|c|}{ Entry Ratio } & \multicolumn{2}{|c|}{ Time Ratio } & \multicolumn{2}{|c|}{ Total Entries } \\
\hline & & $M$ & $S E M$ & $M$ & $S E M$ & $M$ & $S E M$ & $M$ & $S E M$ & $M$ & $S E M$ \\
\hline Saline & 42 & 50.4 & 5.5 & 5.5 & 0.4 & 0.34 & 0.03 & 0.34 & 0.03 & 21.0 & 1.7 \\
\hline Diazepam 1.0 & 10 & 87.2 & $22.2^{*}$ & 0.8 & $0.4 \dagger$ & 0.55 & $0.04 \dagger$ & 0.79 & $0.04 \dagger$ & 27.3 & $3.4^{*}$ \\
\hline Diazepam 1.5 & 10 & 117 & $17 \dagger$ & $0.0 \dagger$ & & 0.59 & $0.04 \dagger$ & 0.82 & $0.03 \dagger$ & 22.4 & 3.8 \\
\hline Diazepam 2.0 & 20 & 78.4 & $8.4^{*}$ & 0.4 & $0.2 \dagger$ & 0.54 & $0.03 t$ & 0.72 & $0.04 \dagger$ & 17.9 & 1.7 \\
\hline
\end{tabular}

Trials 2-6 (30-sec ITI). A significant between-groups difference was observed [three groups treated with diazepam + saline group; $F(3,57)=6.11, p=.001]$. Post hoc paired comparisons following an ANOVA on all groups showed that, at the dose of $2.0 \mathrm{mg} / \mathrm{kg}$, diazepam significantly reduced sequential alternation rates compared with saline $(42.0 \%$ vs. $74.5 \%, p<.01)$. Lower doses $(1.0$ and $1.5 \mathrm{mg} / \mathrm{kg}$ ) also significantly decreased sequential alternation rates $(65 \%$ and $57 \%$, respectively; $p<.05$ for both comparisons).

Trials 7-9 (5-sec ITI). The alternation scores exhibited by all groups at the 5 -sec ITI were significantly higher than the ones observed at the 30-sec ITI ( $p<.05$ for each comparison), and no significant between-groups differences were observed $[F(3,47)=1.37, p=.26]$.

Comparison of Trials 2-6 (30-sec ITI) with Trials 7-9 (5-sec ITI). As suggested by the above analysis, reducing the ITI from $30 \mathrm{sec}$ (Trials 2-6) to $5 \mathrm{sec}$ (Trials 7-9) resulted in an overall increase in sequential alternation rate in diazepam-treated subjects. In particular, the $2.0 \mathrm{mg} /$ $\mathrm{kg}$ group, which, compared to the saline group, was the most impaired across Trials $1-6$ with a 30 -sec ITI, displayed normal sequential alternation rates on the last three trials with a 5 -sec ITI ( $73.3 \%$ vs. $74.3 \%$ for controls; $F<$ 1.0 ). These differences may have resulted either from the reduction of the ITI (from 30 to $5 \mathrm{sec}$ ) or from the position of trials in the series (Trials 2-6 vs. 7-9). The second procedure was designed to determine which of these two factors was responsible for the differential effect of diazepam on sequential alternation rates.

The second procedure was the same as the previous one except that the ITI conditions were reversed with respect to the position of trials in the series (i.e., the ITI was increased from $5 \mathrm{sec}$ (Trials 2-6) to $30 \mathrm{sec}$ (Trials
7-9). The study was performed only with the $2.0 \mathrm{mg} / \mathrm{kg}$ dose, which had induced the more important detrimental effects in the sequential alternation task in the first procedure.

Comparison of Trials 1-6 (5-sec ITI) with Trials 7-9 (30-sec ITI). Results are summarized in Table 2. Diazepam $(2.0 \mathrm{mg} / \mathrm{kg})$ produced an overall significant decrease in sequential alternation rates [treatment; $F(1,18)=$ $8.6, p<.01]$. As in the previous experiment, animals treated with diazepam at $2.0 \mathrm{mg} / \mathrm{kg}$ were not significantly different from the saline animals with the 5-sec ITI $(p>.10)$ but were significantly impaired with the 30 -sec ITI $[F(1,18)=12.9, p<.01]$. An overall analysis performed on pooled results from Procedures 1 and 2 (Table 2) showed that the treatment $\times$ ITI interaction was highly significant $[F(1,39)=5.54, p=.02]$, whereas the treatment $\times$ blocks of trials interaction was not $(p=$ .07 ). This result suggests that the deleterious effect of diazepam at $2.0 \mathrm{mg} / \mathrm{kg}$ on sequential alternation was mainly delay dependent.

\section{EXPERIMENT 2}

Effects of Diazepam Injection Associated or Not With Intramaze Context Change During Retention Trials on Delayed Sequential Alternation Rates

The aims of this experiment were threefold: to determine whether (1) diazepam administered just before a long-term retention trial might disrupt performance, (2) eventual deficits are time dependent, and (3) an intramaze context change occurring during the long-term retention trial might alleviate or reduce the deficits in diazepam-treated mice, as shown in earlier studies of alcohol-treated animals (Béracochéa et al., 1987).

Table 2

Percent Alternation Rates (Means and SEMs) in Sequential Spontaneous Alternation Task (1st Procedure) in Diazepam and Saline-Treated Mice (2nd Procedure) as a Function of Trial Position and Intertrial Interval (ITI)

\begin{tabular}{|c|c|c|c|c|c|c|c|c|c|c|c|c|}
\hline \multirow[b]{4}{*}{ Treatment } & \multicolumn{12}{|c|}{ ITI } \\
\hline & \multicolumn{4}{|c|}{ lst Procedure } & \multicolumn{4}{|c|}{ 2nd Procedure } & \multicolumn{4}{|c|}{ Pooled } \\
\hline & \multicolumn{2}{|c|}{$30 \mathrm{sec}$} & \multicolumn{2}{|c|}{$5 \mathrm{sec}$} & \multicolumn{2}{|c|}{$5 \mathrm{sec}$} & \multicolumn{2}{|c|}{$30 \mathrm{sec}$} & \multicolumn{2}{|c|}{$5 \mathrm{sec}$} & \multicolumn{2}{|c|}{$30 \mathrm{sec}$} \\
\hline & $M$ & $S E M$ & $M$ & $S E M$ & $M$ & $S E M$ & $M$ & $S E M$ & $M$ & $S E M$ & $M$ & $S E M$ \\
\hline Saline & 74.5 & 5.5 & 74.3 & 9.4 & 82.0 & 3.6 & 83.4 & 5.6 & 77.9 & 5.1 & 78.7 & 3.9 \\
\hline Diazepam $(2 \mathrm{mg} / \mathrm{kg})$ & 42.0 & $7.6^{*}$ & 73.3 & 9.7 & 72.0 & 5.3 & 50.0 & $7.5 \dagger$ & 72.7 & 5.4 & 46.0 & $5.3 \dagger$ \\
\hline
\end{tabular}




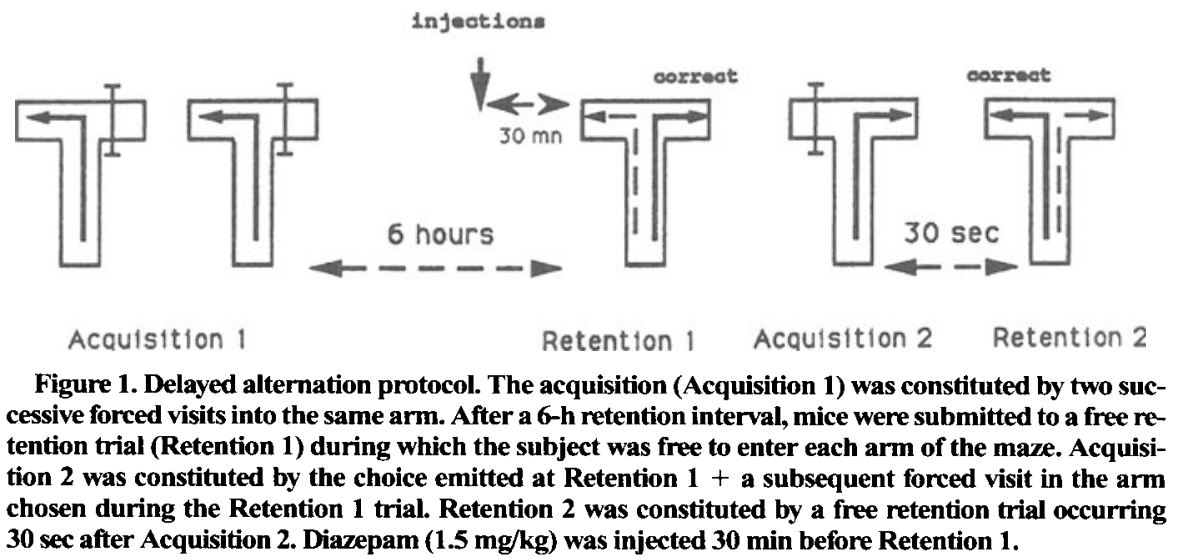

\section{Method}

\section{Delayed Alternation Procedure}

The delayed alternation task was performed in the same T-maze apparatus used in the first experiment. In this procedure (Figure 1), mice were first submitted to an acquisition session (Acq. 1) constituted by two successive forced entries into the same arm of the T-maze, access to the other arm being blocked by a sliding door. Mice were then replaced in the colony room for a 6 -h period. When this time interval had elapsed, mice were tested for memory by a free retention trial (Ret. 1) during which they could freely enter each arm of the maze, the alternation response being to visit the arm opposite to the one visited during the acquisition phase. Once the subjects had entered one arm of the maze, they were confined in that arm for $30 \mathrm{sec}$ and placed again in the start box for a subsequent forced trial, during which they were obliged to reenter the arm chosen at Ret. 1. The 6-h retention trial and the subsequent forced trial constituted, in fact, a second acquisition phase (Acq. 2). Memory was assessed $30 \mathrm{sec}$ later by a free retention trial (Ret. 2) during which mice could freely enter each arm of the maze. Thus, the whole procedure made it possible to study memory for long (Ret. 1) as well as for short $(30-\mathrm{sec})$ delays (Ret. 2). Performance at Ret. 2 allowed us to determine eventual sedative effects of the drug as well as possible detrimental effects of diazepam on behavioral inhibition, on exploration tendencies, and on the motivation to alternate (Figure 2). Indeed, normal performance at the shortest delay (Ret. 2) would indicate that cognitive and motor processes sustaining the alternation behavior function normally, and, in turn, that eventual deficits at Ret. 1 are specifically due to the length of the delay between the acquisition and test trials.

\section{Intramaze Context Change}

This intramaze context change procedure was used in earlier studies and was found to totally alleviate the delayed alternation deficits of alcohol-treated mice (Béracochéa \& Jaffard, 1985; Béracochéa et al., 1987). In this procedure, the intramaze context change was effected by placing a white rectangle cardboard at the end of the central alley of the maze at Ret. 1, whereas the acquisition trials (Acq. 1) were made in usual testing conditions (no intramaze context change); the cardboard was maintained in the maze during subsequent Acq. 2 and Ret. 2 trials. The cardboard did not have any informative value that could help the subjects to choose one goal arm of the maze; it constituted only a simple variation of the intramaze context during Ret. 1.

\section{Experimental Design}

The experiment was performed on independent groups assigned to four conditions: saline-treated subjects $(n=10)$, nontreated $(n=$ $10)$, diazepam-treated $(1.5 \mathrm{mg} / \mathrm{kg})(n=20)$, diazepam-treated $(1.5 \mathrm{mg} / \mathrm{kg})+$ cardboard subjects $(n=26)$.
The diazepam dose in the present experiment was the intermediate one $(1.5 \mathrm{mg} / \mathrm{kg})$ used in the first experiment, which was found to induce memory deficits in the sequential spontaneous alternation task. The $1.5 \mathrm{mg} / \mathrm{kg}$ diazepam dose was preferred over the $2.0 \mathrm{mg} / \mathrm{kg}$ dose because it minimized possible general effects from repeated injections. Indeed, as observed in the previous experiment, the $1.5 \mathrm{mg} / \mathrm{kg}$ dose induced a significant alternation deficit that was less severe than the one resulting from the $2.0 \mathrm{mg} / \mathrm{kg}$ dose. Diazepam was administered i.p. $30 \mathrm{~min}$ only before Ret. 1, according to the same specifications as those described in Experiment 1. A 72-h delay was interpolated between each session (four sessions per condition and per animal). Thus, as a whole, mice receive four injections with a similar dose every time. During Acq. 1 , the number of right and left directions in which the subjects were forced to go was equal, so that turn biases could be eliminated (chance level: $50 \%$ ). During the 6-h delay intervals, animals were replaced in their cage in the colony room.

In the present experiment, we did not test the effects of introducing the cardboard on the alternation performance of saline mice. Indeed, we have already shown in previous experiments using the very same protocol and delay intervals that the cardboard

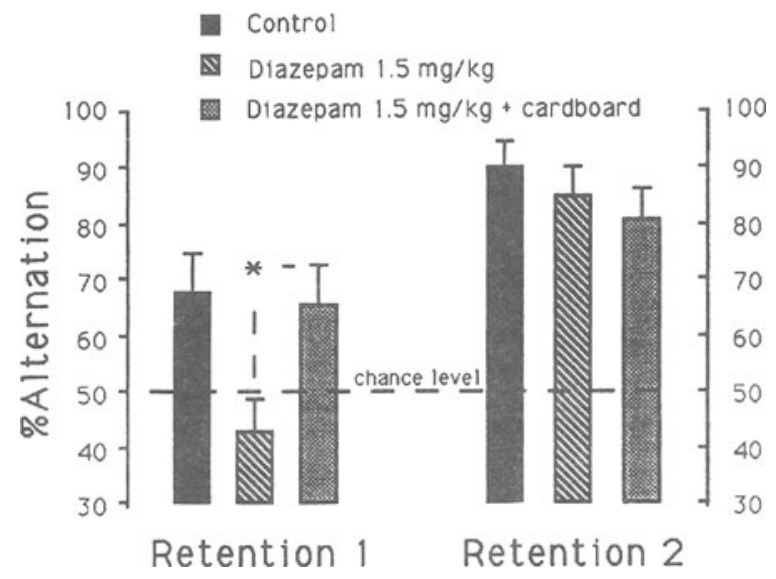

Figure 2. Effects of diazepam administration $(1.5 \mathrm{mg} / \mathrm{kg})$ on delayed alternation rates at Retention 1 (6-h delay) and Retention 2 (30sec delay). Diazepam administration induced a significant decrease of alternation rates at Retention 1 but not at Retention 2. The addition of a cardboard (see text) within the maze during the Retention 1 trial resulted in a dramatic improvement of performance (diazepam + cardboard group) as compared with subjects run in the usual conditions $(p<.03)$. No between-group differences were observed at Retention 2. 
did not significantly modify the alternation score of normal subjects (Béracochéa \& Jaffard, 1985, 1987; Béracochéa et al., 1987; Tako et al., 1988).

\section{Results}

Results are summarized in Figure 2. Since no significant differences were observed between nontreated and saline-treated subjects at either Ret. 1 or Ret. $2(p>.10$ in all comparisons), performances of the two groups were pooled (controls, $n=20$ ) for further statistical comparisons. A global analysis performed on Ret. 1 showed a significant between-groups difference $[F(2,63)$ $=2.95, p=.05]$. More specifically, diazepam-treated animals exhibited a lower delayed sequential alternation rate $(42.5 \% \pm 6.6)$ at Ret. 1 than did controls $[65.5 \% \pm$ $8.8 ; F(1,39)=6.29, p=.02]$, or diazepam-treated + cardboard subjects $[65.4 \% \pm 7.2 ; F(1,45)=5.18, p=$ $.03]$; in contrast, no significant differences were observed at Ret. 1 between diazepam + cardboard and control groups $[F(1,45)=.04]$. Reducing the delay from $6 \mathrm{~h}$ (Ret. 1) to $30 \mathrm{sec}$ (Ret. 2) enhanced the alternation rates $[F(1,63)=23.6, p=.0001]$, but similarly in all groups [treatment $\times$ delay; $F(2,63)=1.14$ ]. At Ret. 2, diazepamtreated mice performed similarly to controls $[85.0 \pm 5.3$ and $90.4 \pm 4.6$, respectively; $F(1,39)=.51$ ]; they also behaved similarly to the diazepam + cardboard group $[78.8 \pm 5.7 ; F(1,45)=0.28]$.

An additional analysis of the data showed that all groups exhibited comparable alternation rates at Ret. 2, whatever the response (alternation vs. repetition) emitted at Ret. $1(88.2 \%, 79.5 \%$, and $92.3 \%$ following alternation for diazepam, diazepam + cardboard, and control groups, respectively, $p>.05$ in all comparisons; $87 \%$, $78 \%$, and $78.5 \%$ following repetition [no alternation] for diazepam, diazepam + cardboard, and control groups, respectively, $p>.05$ in all comparisons).

\section{GENERAL DISCUSSION}

The major findings of the present study are as follows: (1) Diazepam administration produced in BALB/c mice delay-dependent sequential and delayed alternation deficits; and (2) the alternation deficit at long delays in diazepam-treated subjects was alleviated by an intramaze context change occurring just before the retention trial, as compared with the retention scores of drugged subjects run in usual (no intramaze context change) testing conditions.

\section{Delay-Dependent Memory Deficit Induced by Diazepam Administration}

The results of Experiments 1 and 2 showed that retention scores of diazepam-treated mice are dependent on the delay intervals separating the acquisition and subsequent retention trials, both in the sequential and delayed alternation procedures. Indeed, in the sequential procedure, the deficit was a function of the ITI (significant ITI $X$ treatment interaction) but not of the position of the trial in the series (the interaction trials $\times$ treatment was, however, close to the statistical level of significance); thus, sequential alternation rates were significantly reduced on trials separated by a 30 -sec ITI, but not by a 5 sec ITI (Trials 2-6 and 7-9), whatever the position of these trials in the series. These results show that the observed diazepam-induced impairments in sequential alternation rates resulted from alterations in mnemonic processes that sustain the specific information required for alternating from trial to trial during the delay interval. Diazepam induced a delay-dependent working memory deficit. The importance of the delay in inducing deficit was also demonstrated in the delayed sequential alternation procedure, since diazepam-treated animals exhibited a deficit on the first retention trial, occurring $6 \mathrm{~h}$ after the acquisition phase (Ret. 1), whereas they exhibited higher and normal sequential alternation rates on the second retention trial, occurring only $30 \mathrm{sec}$ after the second acquisition phase (Ret. 2). Normal performance at Ret. 2 was found to be independent of the response (alternation or repetition) emitted at Ret. 1; such a finding shows that, at the dose used, the maintenance of information over a short delay interval, as well as encoding processes, is spared by the drug. In addition, normal performance at Ret. 2 indicates that diazepam did not induce sedative or motivational effects that would interfere with performance. Thus, results from Experiments 1 and 2 are in agreement with studies showing that diazepam administration induces deficits in long-term delayed response tasks (Chroback \& Napier, 1992; Ohno, Yamamoto, \& Watanabe, 1992; Stackman \& Walsh, 1992).

It has been suggested that the detrimental effect of diazepam administration on memory is mainly due to a deficit of encoding processes (J. Brown, Lewis, Brown, Horn, \& Bowes, 1982; Lister, 1985). In our experiments, a careful analysis of the results shows that diazepam administration did not induce encoding deficits in the sequential alternation tasks. Indeed, if deficits were due exclusively to impairments of encoding processes, they should have been independent of the delay interval. This was not the case. Thus, in the sequential spontaneous alternation task, administration of diazepam induced a dose-dependent deficit with the 30-sec ITI that was not observed with the 5 -sec ITI; similarly, no deficits were observed at Ret. 2 of the delayed spontaneous alternation task. The apparent discrepancy between our results and studies showing encoding deficits in tasks using a preacquisition drug administration protocol (Chapouthier \& Martin, 1992) might be related to the kind of tasks used to evaluate memory. Indeed, the alternation tasks used in our experiments did not involve important procedural components, since they are based on an innate behavior, whereas most of the studies showing encoding deficits in animals have used behavioral tools involving such procedural components.

\section{Nature of Memory Deficit in Diazepam-Treated Mice}

The introduction of white cardboard at the end of the stem alley just before Ret. 1 alleviated the deficit ob- 
served in diazepam-treated subjects run in usual (no cardboard added in the maze) conditions. Thus, the memoryenhancing effect of the intramaze context change in diazepam-treated mice demonstrated that the specific information required to alternate at Ret. 1 was not forgotten (if that had been the case, the intramaze context change would not have been able to reverse the deficit). One can conclude that diazepam-treated subjects were unable to retrieve in usual conditions the specific information sustaining the delayed alternation response. It follows that the memory-enhancing effect of the cardboard in diazepam-treated mice clearly showed that the diazepam-induced deficit observed in the usual testing condition was due to a difficulty in accessing normally stored information. The fact that the spontaneous alternation deficit was observed at long but not short delay intervals shows that the retrieval impairment of diazepamtreated mice is time dependent.

The interpretation of a selective retrieval impairment in diazepam-treated animals is strengthened by previous findings showing that the intramaze context change did not modify forgetting rates of normal subjects at either short or long delays (Béracochéa \& Jaffard, 1985, 1987; Béracochéa et al., 1987; Tako et al., 1988), as well as the long-term memory impairments induced by aging in a similar delayed alternation task (Béracochéa et al., 1989).

\section{Relationships Between Memory and Emotional Deficits in Diazepam-Treated Mice: A Hypothesis}

It is conceivable that the reduction of anxiety in diazepam-treated mice, as shown in the elevated plusmaze and the open-field tasks, interferes with the ability to engage active searching operations during retrieval at long delay intervals. We have an indirect argument to sustain this hypothesis. Indeed, the memory-facilitating effect of the cardboard in diazepam-treated animals is comparable to the one observed in alcohol-treated mice following the administration of $\beta$-CCM (a BDZ inverse agonist) at doses having anxiogenic effects (Béracochéa et al., 1995). We showed that alcohol-treated mice exhibited large reductions of fear reactions in the elevatedplus maze and the open-field task, similar to the ones induced in the present study by diazepam administrations. The injection of $\beta$-CCM in alcohol-treated animals reestablished normal anxiety-like reactions and concomitantly alleviated the retrieval memory deficits of experimental mice. In the present study, we can hypothesize that the cardboard placed in the maze at Ret. 1 might have had an anxiogenic value that may have attenuated the anxiolytic effects of the drug. Indeed, placing a cardboard in the maze induced an important intramaze context change, and it is well known that placing a rodent in a new environment induces anxiogenic-like behavioral patterns (Gray, 1982). Thus, the cue may stimulate retrieval processes in a manner comparable to $\beta$-CCM in alcohol-treated animals, via an increase of the anxiety state of the subject. However, even though a functional interaction between brain systems subserving both emotion and memory (Walsh \& Stackman, 1992) have been demonstrated, further studies are required to firmly establish a clear-cut relationship between the reduction of anxiety and the retrieval deficit observed following diazepam administration in the present experiment, since it has been reported that memory impairments have occurred in rodents following BDZ administration without obvious anxiolytic or anxiogenic effects (Chapouthier et al., 1991; MacNamara \& Skelton, 1993).

In conclusion, our study shows that the disruptive effects of diazepam administration on memory are not due to encoding processes, but to a time-dependent retrieval impairment. The resemblance between the effects of diazepam administration reported in the present experiments and those observed following long-term alcohol consumption in previous studies (Béracochéa et al., 1995; Béracochéa et al., 1987) strengthens the hypothesis that GABA/BDZ dysfunctions might be responsible, at least in part, for the retrieval deficits observed in amnesia of alcoholic origin. Such a point of view is reinforced by findings showing that diencephalic areas, which are severely damaged in Korsakoff patients, also exhibit important densities of BDZ receptor sites (Eymin et al., 1992).

\section{REFERENCES}

Belzung, C., Misslin, R., Vogel, E., Dodd, R. H., \& ChapouTHIER, G. (1987). Anxiogenic effects of methyl- $\beta$-carboline-3carboxylate in a light/dark choice situation. Pharmacology. Biochemistry \& Behavior, 28, 29-33.

BÉracochÉA, D. J., \& JAFFARD, R. (1985). Memory deficits subsequent to chronic consumption of alcohol in mice: An analysis based on spontaneous alternation behavior. Behavioural Brain Research, $15,15-25$.

BÉRACOCHÉA, D. J., \& JAFFARD, R. (1987). Impairment of spontaneous alternation behavior in sequential test procedures following mammillary body lesions in mice: Evidence for time-dependent interferencerelated memory deficits. Behavioral Neuroscience, 101, 187-197.

BéracochÉA, D. [J.], KRAzem, A., \& JafFard, R. (1995). Methyl betacarboline-3-carboxylate reverses the working memory deficits induced either by chronic alcohol consumption or mammillary body lesions in BALB/c mice. Psychobiology, 23, 52-58.

Béracochéa, D. J., Lescaudron, L., Tako, A., Verna, A., \& JafFARD, R. (1987). Build-up and release from proactive interference during chronic ethanol consumption in mice: A behavioral and neuroanatomical study. Behavioural Brain Research, 25, 63-74.

BÉRACOCHÉA, D. J., TAKo, A., \& J JFFARD, R. (1989). Accelerated rates of forgetting of spatial information during aging and long-term ethanol consumption in mice: Evidence for two distinct forms of amnesia. Psychobiology, 17, 358-362.

Brown, J., LewIS, V., Brown, M., Horn, G., \& Bowes, J. B. (1982). A comparison between transient amnesias induced by two drugs (diazepam or lorazepam) and amnesia of organic origin. Neuropsychologia, 20, 55-70.

Brown, M. W., Brown, J., \& Bowes, J. B. (1989). Absence of priming coupled with substantially preserved recognition in lorazepaminduced amnesia. Quarterly Journal of Experimental Psychology, 41A, 599-617.

Chapouthier, G., \& Martin, B. (1992). $\beta$-carbolines: From memory towards genetics. Cahiers de Psychologie Cognitive, 12, 423-458.

Chapouthier, G., Raffalli-Sebille, M.-J., Venault, P., Simiand, J., \& DoDD, R. H. (1991), Comparison between the effects of the benzodiazepine receptor ligands methyl beta-carboline-3-carboxylate and diazepam in two learning situations in mice. Psychobiology, 19, 5863.

Chrobak, J. J., \& NAPIER, T. C. (1992). Delayed non-matched to sample performance in the radial arm maze: Effects of dopaminergic and gabaergic agents. Psychopharmacology, 108, 72-78. 
Danion, J. M., Weingartner, H., File, S. E., JafFard, R., Sunderland, T., Tulving, E., \& WarburTon, D. M. (1993). Pharmacology of human memory and cognition: Illustrations from the effects of benzodiazepines and cholinergic drugs. Journal of Pharmacology, 7, 371-377.

Danion, J. M., Zimmmermann, M. A., Willard-Schroeder, D., GRANGÉ, D., \& Singer, L. (1989). Diazepam induces a dissociation between explicit and implicit memory. Psychopharmacology, 99, 238-243.

DENNENBERG, V. H. (1969). Open-field behaviour in the rat: What does it mean? In E. Tobach (Ed.), Experimental approaches to the study of behavior (Annals of the New York Academy of Sciences, Vol. 159, pp. 852-859). New York: New York Academy of Sciences.

Divac, I., WITMARK, R. G. E., \& GADE, A. (1975). Spontaneous alternation in rats with lesions in the frontal lobes: An extension of the frontal lobe syndrome. Physiology \& Behavior, 3, 39-42.

DudChenko, P., \& SARTER, M. (1992). Behavioral microanalysis of spatial delayed alternation performance: Rehearsal through overt behavior, and effects of scopolamine and chlordiazepoxide. Psychopharmacology, 107, 263-270.

Eymin, C., Kopp, N., Laurent, B., Martin, D., Simon, L., \& MiaCHON, S. (1992). Central benzodiazepine-binding sites in human cerebral structures associated with memory processes. Dementia, 3 , 232-238.

FANG, J. C., Hinkichs, J. V., \& Gonheim, M. M. (1987). Diazepam and memory: Evidence for spared memory function. Pharmacology, Biochemistry \& Behavior, 28, 347-352.

File, S. E., Skelly, A. M., \& Girdler, N. M. (1992). Midazolaminduced retrieval impairments revealed by the use of flumazenil: $\mathrm{A}$ study in surgical dental patients. Journal of Psychopharmacology, 6 , 81-87.

Gonheim, M. M., Block, R. L., Sum Ping, S. T., El-Zahaby, H. M. \& HinRICHS, J. V. (1993). The interactions of midazolam and flumazenil on human memory and cognition. Anesthesiology, 79. 1183-1192.

Gonheim, M. M., Hinrichs, J. V., \& Mewaldt, S. P. (1984). Doseresponse analysis of the behavioral effects of diazepam: I. Learning and memory. Psychopharmacology, 82, 291-295.

Gonheim, M. M., \& Mewaldt, S. P. (1975). Effects of diazepam and scopolamine on storage, retrieval and organizational processes in memory. Psychopharmacologia, 44, 257-262.

GRANT, D. S. (1981). Intertrial interference in rat short-term memory. Journal of Experimental Psychology: Animal Behavior Processes, 7, 217-227.

GRAY, J. (1982). The neuropsychology of anxiety. New York: Oxford University Press.

Herremans, A. H. J., Huzen, T. H., Olivier, B., \& Slangen, J. L. (1995). Benzodiazepine receptor ligands have no specific action on working memory in a delayed conditional discrimination task in rats. Behavioural Pharmacology, 6, 238-244.

JAFFARD, R., \& CARDO, B. (1976). Évitement passif chez deux lignées de souris consanguines: Réponse émotionnelle conditionnée et évitement spécifique. Comptes Rendus de l'Academie des Sciences de Paris, 282D, 207-209.

KESNER, R. P. (1986). Neurobiological views of memory. In J. L. Martinez \& R. P. Kesner (Eds.), Learning and memory: A biological view (pp. 399-438). Orlando, FL: Academic Press.

LISTER, R. G. (1985). The amnesic action of benzodiazepines in man. Neuroscience \& Biobehavioral Reviews, 9, 87-94.
MCNamara, R. K., \& Skelton, R. W. (1993). Benzodiazepine receptor antagonists flumazenil and CGS 8216 and inverse-agonist $\beta$ CCM enhance spatial learning in the rat: Dissociation from anxiogenic actions. Psychobiology, 21, 101-108.

MorrIs, R. G. M. (1983). An attempt to dissociate "spatial mapping" and "working-memory" theories of hippocampal function. In W. Seifert (Ed.), Neurobiology of the hippocampus (pp. 405-432). New York: Academic Press.

Ohno, M., Yamamoto, T., \& Watanabe, S. (1992). Intrahippocampal injections of benzodiazepine and muscimol impair working memory but not reference memory of rats in the three-panel runway task. European Journal of Pharmacology, 219, 245-251.

O' KeEFE, J. (1979). Hippocampal function: Does the working memory hypothesis work? Should we retire the cognitive map theory? Behavioral \& Brain Sciences, 2, 339-343.

Pellow, S., Chopin, P., File, S. E., \& Briley, M. (1985). Validation of open:closed arm entries in an elevated plus-maze as a measure of anxiety in the rat. Journal of Neuroscience Methods, 14, 149-167.

Polster, M. R., McCarthy, R. A., O'Sullivan, G., Gray, P. A., \& PARK, G. R. (1993). Midazolam-induced amnesia: Implications for the implicit/explicit memory distinction. Brain \& Cognition, 22, 244-265.

Roberts, A. R., \& Dale, R. H. (1981). Remembrance of places lasts: Proactive inhibition and patterns of choice in rat spatial memory. Learning \& Motivation, 12, 261-281.

SARTER, M. (1990). Retrieval of well-learned propositional rules: Insensitive to changes in activity of individual neurotransmitter systems? Psychobiology, 18, 451-459.

SCHACTER, D. L. (1987). Implicit expressions of memory in organic amnesia: Learning of new facts and associations. Human Neurobiology, 6, 107-118.

Stackman, R. W., \& WALSH, T. J. (1992). Chlordiazepoxide-induced working memory impairments: Site specificity and reversal by flumazenil (RO 15-1788). Behavioral \& Neural Biology, 57, 233243.

TAKo, A. N., BÉRACOChÉA, D. J., \& JAFFARD, R. (1988). Accelerated rate of forgetting of spatial information following mamillary-body lesions in mice: Effects of context change on retention-test performance. Psychobiology, 16, 45-53.

Тніевот, М. H. (1985). Some evidence for amnesic-like effects of benzodiazepines in animals. Neuroscience \& Biobehavioral Reviews, 9, 95-100.

Thомаs, G. J. (1984). Memory: Time-binding in organism. In L. R. Squire \& N. Butters (Eds.), Neuropsychology of memory (pp. 374384). New York: Guilford Press.

Twersky, R. S., Hartung, J., Berger, B. J., McClain, J., \& BearoN, C. (1993). Midazolam enhances anterograde but not retrograde amnesia in pediatric patients. Anesthesiology, 78, 51-55.

Venault, P., Chapouthier, G., Prado de Carval ho, L., Simiand, J., Morre, M., Dodd, R. H., \& Rossier, J. (1986). Benzodiazepine impairs and $\beta$-carboline enhances performance in learning and memory tasks. Nature, 321, 864-866.

WALSH, T., \& STACKMAN, R. (1992). Modulation of memory by benzodiazepine-acetylcholine interactions. In E. D. Levin, M. W. Decker, \& L. L. Butcher (Eds.), Neurotransmitter interactions and cognitive functions (pp. 312-328). Boston: Birkhauser.

(Manuscript received December 29, 1995; revision accepted for publication December 5, 1996.) 